\title{
Safe Asset Shortages and Asset Price Bubbles
}

\author{
Kosuke Aoki \\ University of Tokyo \\ Tomoyuki Nakajima \\ Kyoto University / The Canon Institute for Global Studies
}

Kalin Nikolov

European Central Bank

May 2014

※Opinions expressed or implied in the CIGS Working Paper Series are solely those of the author, and do not necessarily represent the views of the CIGS or its sponsor.

※ CIGS Working Paper Series is circulated in order to stimulate lively discussion and comments.

※Copyright belongs to the author(s) of each paper unless stated otherwise. 


\title{
Safe Asset Shortages and Asset Price Bubbles*
}

\author{
Kosuke Aoki (University of Tokyo) ${ }^{\dagger}$ \\ Tomoyuki Nakajima (Kyoto University and CIGS) $)^{\ddagger}$ \\ Kalin Nikolov (European Central Bank)§
}

May 2014

\begin{abstract}
We build a model economy in which a shortage of safe assets can create conditions for intrinsically useless 'safe' bubble assets to circulate at a positive price. Our environment features infinitely lived individuals who are not subject to credit constraints but who face uninsurable idiosyncratic production risk. Bubbly equilibria exist when safe assets offer real returns below the growth rate of the economy. Bubble assets circulate at a positive price only if they offer returns which are safe relative to production returns. These 'safe' bubbles reduce consumption volatility but exert a contractionary effect on the economy.
\end{abstract}

JEL Classification: E3.

Key Words: Safe Asset Shortage, Asset Price Bubbles.

\footnotetext{
${ }^{*}$ We thank an anonymous referee and the editors of the Journal for useful comments and suggestions.

${ }^{\dagger}$ Corresponding author. Faculty of Economics, University of Tokyo, 7-3-1 Hongo, Bunkyo, Tokyo 113-0033 Japan. E-mail: kaoki@e.u-tokyo.ac.jp

${ }^{\ddagger}$ Institute of Economic Research, Kyoto University, Kyoto 606-8501, Japan. Email: tomoyuki.nakajima@gmail.com

${ }^{\S}$ Research Department, European Central Bank, Kaiserstrasse 29, Frankfurt-am-Main, email: kalin.nikolov@ecb.int
} 


\section{Introduction}

The structural shortage of safe assets has become a major policy concern over the past several years. Excessive creation of 'quasi-safe' assets was blamed for the build-up to the Subprime crisis. Since the Great Recession and the European Sovereign Debt crisis, many private and public assets have lost their 'ultra-safe' status worsening the structural shortage of safe assets. As a result, world-wide risk-free interest rates have fallen and the remaining asset classes which are perceived to be safe (ranging from US Treasuries to London real estate) have appreciated in price to record high levels, prompting discussions of whether new bubbles are popping up to replace the old ones.

In this paper we offer a rational bubble-based theory to explain the economy's tendency to overvalue financial assets which are perceived to be safe. In our framework risk averse individuals want to hold safe assets in order to smooth consumption across states of nature. They are willing to pay a large premium over riskier assets when such riskless securities are in short supply. When this drives the interest rate on risk-free assets below the growth rate of the economy, non-fundamental asset valuations become possible in equilibrium. Intrinsically worthless assets which are believed to be safe can deliver capital gains that match the very low safe rate of return without violating feasibility constraints.

When such 'safe bubbles' appear in equilibrium, they reduce economic growth. This is because they crowd out investment in productive assets, and in our endogenous (AK) growth framework, this slows down the rate of economic expansion.

Nevertheless, despite their negative impact on economic growth, bubbles are unambiguously welfare improving in our model because they help to cor- 
rect the distortion caused by missing insurance markets. The bubble provides the economy with a safe asset which improves the ability of households to smooth their consumption in the face of large idiosyncratic and uninsurable productivity shocks. Safe bubbly securities circulate through the economy as those households who experience bad idiosyncratic productivity realisations sell bubbles to those who experience good productivity realisations. The result is lower wealth and consumption volatility at the individual level.

In addition to the consumption smoothing benefits, the bubble has a large wealth effect which increases the level of consumption in the short run and, due to discounting, this helps to offset to some extent the cost of lower consumption growth on welfare. In total, whenever bubbles exist in our model, their consumption smoothing benefits and their positive wealth effect always dominate the reduction in long run growth, raising aggregate welfare.

This is not to say that bubbles are a costless solution to missing insurance markets in our model. They improve consumption smoothing only at the cost of diverting funds away from capital investment which is dynamically efficient according to the definition of Abel et al. (1989). This is why the bubbly equilibrium in our model does not implement the first best: it delivers welfare which is lower than under complete markets.

There are a number of other papers that have studied the issue of the impact of bubbles on long run economic growth and welfare. Grossman and Yanagawa (1993) show in a model with capital externalities that bubbles on intrinsically useless assets may exist due to a wedge between the private and social return on capital. When bubbles exist, they divert resources from capital accumulation and retard economic growth. Since growth is already too low due to the presence of capital externalities, bubbles reduce welfare. Olivier (2000) has shown that when the bubble is attached to capital goods, it can actually 
increase economic growth.

More recent papers have also examined the importance of borrowing constraints for the relationship between bubbles, growth and welfare. Miao and Wang (2014) qualify the result of Olivier (2000) by showing that only bubbles attached to sectors that generate significant aggregate externalities increase growth and welfare. Those bubbles attached to non-externality generating activities are detrimental to welfare even though all bubbles help to relax credit constraints in Miao and Wang (2014).

Unlike Grossman and Yanagawa (1993) and Miao and Wang (2014), our model features no externalities and private and social optima coincide. Therefore, whenever bubbles exist they increase welfare. In contrast, the existence of capital externalities in Grossman and Yanagawa (1993) and Miao and Wang (2014) may lead to a situation in which bubbles crowd out investment in a way that is privately optimal but socially detrimental.

Similarly to our paper, Hirano and Yanagawa (2010) abstract from capital externalities and use an AK growth model. They assume heterogeneous entrepreneurs and credit constraints and show that bubbles may increase or retard economic growth depending on the tightness of collateral constraints. However, bubbles are always welfare improving in their model because they help to provide savers with higher yielding assets. This reduces the difference in the portfolio rates of return of heterogeneous entrepreneurs and helps to improve consumption smoothing over time. Our model abstracts from borrowing constraints and consumption smoothing over time is not distorted. We instead focus on missing markets for insurance against idiosyncratic production risk and the safe bubble asset increases welfare in our framework because it allows improved consumption smoothing across states of nature.

Our paper also offers a contribution to our understanding of the conditions 
for bubble existence. We generate an asset price bubble in an environment with infinitely lived consumer-producers who face uninsurable idiosyncratic production risk but are not subject to borrowing constraints. Bubbles arise in our model not because of a shortage of means of saving (as in most other papers in the rational bubbles literature) but due to a shortage of riskless assets.

In this regard, our work carries many parallels with the literature on fiat money as a means of self-insurance against idiosyncratic income risk started by Bewley $(1980,1986)$. Recent contributions to this strand of literature include, for example, Kitagawa (1994, 2001) and Green and Zhou (2005). Our 'bubble asset' is indeed very similar to fiat money in Bewley (1980): it is an intrinsically useless asset which may trade above its fundamental value (which is zero) because it allows agents to smooth consumption better ${ }^{1}$. There are some important difference too. For example, our mechanism does not rely on restrictions on private credit whereas the existence of fiat money in Bewley (1980) does. In addition, we consider stochastic bubbles which can lose value suddenly whereas models on fiat money usually do not consider this possibility.

The paper is organised as follows. Section 2 outlines the structure of the model and derives the equilibrium without bubbles. Section 3 describes the key features of the balanced growth path of our economy with safe bubbles while section 4 extends the analysis to the case of stochastic bubbles. Section 5 concludes.

\footnotetext{
${ }^{1}$ This similarity is also shared in many papers on rational bubble, including the classic paper by Tirole (1985), and also in recent papers such as Farhi and Tirole (2012), Grossman and Yanagawa (1993), Hirano and Yanagawa (2010). In Miao and Wang (2014), however, bubbles are attached to productive capital rather than to intrinsically useless assets.
} 


\section{The benchmark model without bubbles}

\subsection{The Economic Environment}

Our model economy is a stochastic $A K$ model with incomplete markets. In this section we describe the benchmark model without bubbles. Bubbles are introduced in the following sections.

The economy consists of a continuum of individuals indexed by $i \in[0,1]$. They have identical log preferences given by

$$
E_{0} \sum_{t=0}^{\infty} \beta^{t} \ln c_{t}^{i}
$$

where $\beta \in(0,1)$ is the discount factor and $c_{t}^{i}$ is the amount of consumption of individual $i$ in period $t .^{2}$

Each individual $i$ produces output $y_{t}^{i}$ using the following production technology

$$
y_{t}^{i}=\theta_{t}^{i} A k_{t-1}^{i},
$$

which uses capital $k_{t}^{i}$ as input. Aggregate productivity, $A$, is constant over time. Each individual productive project is subject to an idiosyncratic productivity shock $\theta_{t}^{i}$ which realizes at the beginning of period $t$. It is i.i.d. across individuals and over time, strictly positive, and has unit mean: $E_{t-1}\left[\theta_{t}^{i}\right]=1$. Given the i.i.d. assumption, we sometimes express idiosyncratic shocks as $\theta$ without scripts $t$ or $i$.

In this benchmark model, we assume that physical capital is the only asset available to each individual. In particular, there are no insurance markets

\footnotetext{
${ }^{2}$ Our argument below can easily be extended to the case with more general preferences such as Epstein-Zin preferences. Our choice of the logarithmic utility is solely to simplify the exposition.
} 
for idiosyncratic productivity shocks $\theta_{t}^{i}{ }^{3}$ We also abstract from borrowing and lending across individuals, but this is without loss of generality. It is straightforward to show that they have no incentive to borrow or lend given our assumption that idiosyncratic shocks $\theta_{t}^{i}$ are i.i.d. across individuals and over time. ${ }^{4}$

The budget constraint of each individual is expressed as

$$
c_{t}^{i}+k_{t}^{i}=\theta_{t}^{i} A k_{t-1}^{i},
$$

with the initial condition $k_{-1}^{i}>0$ for all $i^{5}$. We impose the natural debt limit: $k_{t}^{i} \geq 0$ for all $i$ and $t$.

\subsection{Utility Maximization}

The first-order condition for utility maximization is, for each $t$ and $i$,

$$
E_{t}\left[\frac{\beta c_{t}^{i}}{c_{t+1}^{i}} \theta_{t+1}^{i} A\right]=1
$$

The transversality condition is

$$
\lim _{j \rightarrow \infty} E_{t}\left[\frac{\beta^{j} c_{t}^{i}}{c_{t+j}^{i}} k_{t+j}^{i}\right]=0 .
$$

\footnotetext{
${ }^{3}$ Households do have incentive to insure each other against the idiosyncratic shock, but we assume that it is not possible. This may be, for example, because the realisation of $\theta^{i}$ is not verifiable.

${ }^{4} \mathrm{~A}$ similar property is discussed in previous studies such as Constantinides and Duffie (1996), Saito (1998), and Krebs (2003), among others.

${ }^{5}$ Here, we assume that physical capital fully depreciates in each period. This is again without loss of generality. Suppose that the depreciation is $\delta \in[0,1]$. Then the right-handside of the budget constraint would become $\left(\theta_{t}^{i} A+1-\delta\right) k_{t-1}^{i}$. Let $\tilde{A}=A+1-\delta$, and $\tilde{\theta}_{t}^{i}=\left(\theta_{t}^{i} A+1-\delta\right) / \tilde{A}$. Thus, the model with the depreciation rate $\delta$ is isomorphic to our model with $\tilde{\theta}_{t}^{i}$ and $\tilde{A}$.
} 
We solve for the utility maximization problem by the 'guess-and-verify' method. Let us guess that the solution to the utility maximization problem is given by

$$
\begin{gathered}
c_{t}^{i}=(1-\beta) \theta_{t}^{i} A k_{t-1}^{i}, \\
k_{t}^{i}=\beta \theta_{t}^{i} A k_{t-1}^{i} .
\end{gathered}
$$

Then

$$
c_{t}^{i}=\frac{1-\beta}{\beta} k_{t}^{i},
$$

and

$$
c_{t+1}^{i}=(1-\beta) \theta_{t+1}^{i} A k_{t}^{i} .
$$

It follows that

$$
\frac{\beta c_{t}^{i}}{c_{t+1}^{i}} \theta_{t+1}^{i} A=1
$$

Thus, the first-order condition (3) is satisfied. To see the transversality condition is satisfied, notice that

$$
\frac{k_{t+j}^{i}}{c_{t+j}^{i}}=\frac{\beta}{1-\beta} .
$$

It follows that

$$
\lim _{j \rightarrow \infty} E_{t}\left[\frac{\beta^{j} c_{t}^{i}}{c_{t+j}^{i}} k_{t+j}^{i}\right]=\lim _{j \rightarrow \infty} \beta^{j} \frac{\beta}{1-\beta} c_{t}^{i}=0,
$$

for any given $c_{t}^{i}$. This completes the proof that (5) and (6) provide the solution to the utility maximization problem of individual $i$. 


\section{$2.3 \quad$ Aggregation}

The competitive equilibrium in the benchmark model is obtained simply by aggregating the solution to individual utility maximization problems:

$$
\begin{gathered}
C_{t}=(1-\beta) A K_{t-1}, \\
K_{t}=\beta A K_{t-1},
\end{gathered}
$$

where $C_{t}$ and $K_{t}$ are aggregate consumption and capital stock in period $t$, respectively. Thus, the competitive equilibrium in the benchmark economy is a balanced growth path, where aggregate output, consumption, and capital grow at the same rate. Let $\hat{G}$ denote this growth rate:

$$
\hat{G}=\beta A \text {. }
$$

It is convenient to define the real interest rate, $\hat{R}$, for the benchmark economy under the assumption that there is a risk-free asset with zero net supply. That is,

$$
\hat{R}_{t}=\left(E_{t}\left[\frac{\beta c_{t}^{i}}{c_{t+1}^{i}}\right]\right)^{-1},
$$

which yields

$$
\hat{R}_{t}=\hat{R} \equiv\left(E\left[\frac{1}{\theta A}\right]\right)^{-1}
$$

Note that a larger risk, that is, a greater variance of $\theta$, reduces the interest

rate $\hat{R}$. This is a standard property stemming from risk aversion and can be seen from a second order Taylor expansion of (15):

$$
\hat{R} \approx \frac{A}{1+\operatorname{var}(\theta)}
$$




\section{Safe bubbles}

In this section, we show that our model economy allows for bubbles. We begin with the case where bubbles yield a constant rate of return. Stochastic bubbles are studied in the next section. Suppose that the economy possesses a 'bubble asset' of aggregate quantity, $M$, which has no intrinsic value. Let $\mu_{t}$ denote its price in period $t$. In this section we restrict our attention to the case where $\left\{\mu_{t}\right\}_{t=0}^{\infty}$ is a deterministic sequence. Of course, there always exists an equilibrium with $\mu_{t}=0$ for all $t$, which is the one considered in the previous section. In what follows, we shall assume that $\mu_{t}>0$ for all $t$, and derive the necessary and sufficient condition for the existence of equilibria with valued bubbles.

\subsection{Utility maximization}

Let $m_{t}^{i}$ denote the holding of the bubble asset by individual $i$ in period $t$. Then his/her budget in period $t$ is

$$
c_{t}^{i}+k_{t}^{i}+\mu_{t} m_{t}^{i}=\theta_{t}^{i} A k_{t-1}^{i}+\mu_{t} m_{t-1}^{i},
$$

with non-negative constraints $k_{t}^{i}, m_{t}^{i} \geq 0$. The initial asset holdings are given: $k_{-1}^{i}, m_{-1}^{i}>0$. Let $R_{t+1}$ denote the gross rate of return on the bubble asset:

$$
R_{t+1}=\frac{\mu_{t+1}}{\mu_{t}}
$$

which is well defined and strictly positive under the assumption that $\mu_{t}>0$ for all $t$. Then the first-order conditions for utility maximization become:

$$
E_{t}\left[\frac{\beta c_{t}^{i}}{c_{t+1}^{i}} \theta_{t+1}^{i} A\right] \leq 1, \quad\left(\text { with equality if } k_{t}^{i}>0\right)
$$


and

$$
E_{t}\left[\frac{\beta c_{t}^{i}}{c_{t+1}^{i}} R_{t+1}\right] \leq 1, \quad\left(\text { with equality if } m_{t}^{i}>0\right)
$$

The transversality condition is

$$
\lim _{j \rightarrow \infty} E_{t}\left[\frac{\beta^{j} c_{t}^{i}}{c_{t+j}^{i}}\left(k_{t+j}^{i}+\mu_{t+j} m_{t+j}^{i}\right)\right]=0 .
$$

The utility maximization problem can be solved using a 'guess-and-verify' method as in the previous section. First let us define the share of household wealth invested in physical capital $\eta_{t} \in[0,1]$ by

$$
\eta_{t}=\underset{\eta \in[0,1]}{\arg \max } E_{t}\left[\log \left[\theta A \eta+R_{t+1}(1-\eta)\right]\right]
$$

Notice that $\eta_{t}$ does not depend on $i$ because of our assumption that idiosyncratic shocks are i.i.d.. The first-order condition for an interior solution $\eta_{t} \in(0,1)$ is

$$
E_{t}\left[\frac{\theta A-R_{t+1}}{\theta A \eta_{t}+R_{t+1}\left(1-\eta_{t}\right)}\right]=0 .
$$

The corner solutions are obtained in the following cases:

$$
\begin{array}{ll}
\eta_{t}=0 \quad \text { if } & E_{t}\left(\frac{\theta A}{R_{t+1}}\right) \leq 1 \\
\eta_{t}=1 \quad \text { if } & E_{t}\left(\frac{R_{t+1}}{\theta A}\right) \leq 1
\end{array}
$$

Given $\left\{\eta_{t}\right\}_{t=0}^{\infty}$, we guess that the solution to the utility maximization problem is given as follows:

$$
\begin{gathered}
c_{t}^{i}=(1-\beta)\left(\theta_{t}^{i} A k_{t-1}^{i}+\mu_{t} m_{t-1}^{i}\right), \\
k_{t}^{i}=\beta \eta_{t}\left(\theta_{t}^{i} A k_{t-1}^{i}+\mu_{t} m_{t-1}^{i}\right)
\end{gathered}
$$


and

$$
\mu_{t} m_{t}^{i}=\beta\left(1-\eta_{t}\right)\left(\theta_{t}^{i} A k_{t-1}^{i}+\mu_{t} m_{t-1}^{i}\right)
$$

We now establish that these allocations satisfy the first-order conditions (19)(20) and the transversality condition (21).

We use (26)-(28) to obtain

$$
\frac{\beta c_{t}^{i}}{c_{t+1}^{i}}=\left[\theta A \eta_{t}+R_{t+1}\left(1-\eta_{t}\right)\right]^{-1}
$$

Consider any period $t$ and individual $i$. Suppose first that $\eta_{t} \in(0,1)$. Then our candidate solution is interior in period $t: k_{t}^{i}, m_{t}^{i}>0$. It follows from (23) and (29) that

$$
E_{t}\left[\frac{\beta c_{t}^{i}}{c_{t+1}^{i}} \theta_{t+1}^{i} A\right]=E_{t}\left[\frac{\beta c_{t}^{i}}{c_{t+1}^{i}} R_{t+1}\right]
$$

Then note that

$$
\begin{aligned}
1 & =E_{t}\left[\frac{\theta A \eta_{t}+R_{t+1}\left(1-\eta_{t}\right)}{\theta A \eta_{t}+R_{t+1}\left(1-\eta_{t}\right)}\right] \\
& =E_{t}\left[\frac{R_{t+1}}{\theta A \eta_{t}+R_{t+1}\left(1-\eta_{t}\right)}\right] \\
& =E_{t}\left[\frac{\beta c_{t}^{i}}{c_{t+1}^{i}} R_{t+1}\right] .
\end{aligned}
$$

where (23) is used for the second equality, and (29) is used for the the third one. Therefore we verify that equation (20) holds with equality. A similar argument verifies that equation (19) holds with equality. Thus, our candidate solution satisfies the first-order conditions (19) and (20) when $\eta_{t} \in(0,1)$.

Next suppose that $\eta_{t}=0$. Then $k_{t}^{i}=0$, and we need to show that (19) holds with inequality. When $\eta_{t}=0$, (29) implies that

$$
E_{t}\left[\frac{\beta c_{t}^{i}}{c_{t+1}^{i}} \theta A\right]=E_{t}\left[\frac{\theta A}{R_{t+1}}\right]<1
$$


where the last inequality follows from (24). This implies that (19) is satisfied with inequality by our candidate solution. A similar argument can be used to show that when $\eta_{t}=1, m_{t}^{i}=0$ and (20) holds with inequality.

Finally consider the transversality condition (21). Using (26)-(28), we obtain

$$
\frac{k_{t+j}^{i}+\mu_{t+j} m_{t+j}^{i}}{c_{t+j}^{i}}=\frac{\beta}{1-\beta} .
$$

It follows that

$$
\lim _{j \rightarrow \infty} E_{t}\left[\frac{\beta^{j} c_{t}^{i}}{c_{t+j}^{i}}\left(k_{t+j}^{i}+\mu_{t+j} m_{t+j}^{i}\right)\right]=\lim _{j \rightarrow \infty} \beta^{j} c_{t}^{i} \frac{\beta}{1-\beta}=0 .
$$

This completes the proof that our candidate is indeed the solution to the utility maximization problem of each individual.

\subsection{Balanced growth path with bubbles}

As in other models of rational bubbles, there exists a continuum of equilibria with bubbles. Here we study the equilibrium in which the bubble asset yields a constant return: $R_{t}=R$ for all $t .{ }^{6}$ We shall show that such an equilibrium exhibits the balanced growth property: aggregate output, aggregate capital, and aggregate bubbles all grow at a constant rate. We normalize the aggregate amount of the bubble asset to unity: $M=1$.

Since $R_{t}$ is constant, (22) implies that $\eta_{t}$ is constant as well. Because our utility function satisfies the Inada condition, $\eta>0$ in equilibrium. We shall derive the condition for the existence of equilibrium with $\eta<1$.

Given the solution to the utility maximization problem, the aggregate consumption, $C_{t}$, aggregate capital stock, $K_{t}$, and the value of bubbles, $\mu_{t}$ are

\footnotetext{
${ }^{6}$ There is also continuum of equilibria in which the bubble is declining as a share of GDP.
} 
given by

$$
\begin{gathered}
C_{t}=(1-\beta)\left(A K_{t-1}+\mu_{t}\right), \\
K_{t}=\beta \eta\left(A K_{t-1}+\mu_{t}\right), \\
\mu_{t}=\beta(1-\eta)\left(A K_{t-1}+\mu_{t}\right) .
\end{gathered}
$$

From (36) and (37), we obtain

$$
\mu_{t}=\frac{\beta(1-\eta)}{1-\beta(1-\eta)} A K_{t-1}
$$

From equations (36) and (38), bubbles and capital grow at the same constant rate:

$$
G^{*} \equiv \frac{K_{t+1}}{K_{t}}=\frac{\beta \eta A}{1-\beta(1-\eta)}=\frac{\mu_{t+1}}{\mu_{t}}=R^{*}
$$

Balanced growth equilibrium with valued bubbles exists if and only if the solution $\eta$ in (22) is interior with $R_{t+1}=R^{*}$. Let $\eta^{*}$ be the solution to that problem. First, notice that $E\left(\theta A / R^{*}\right)>1$, so that $\eta^{*}>0$ as implied by (24). Next, (39) implies that

$$
E\left(\frac{R}{\theta A}\right)=E\left(\frac{1}{\theta}\right) \frac{\beta \eta}{1-\beta(1-\eta)}
$$

which is an increasing function of $\eta$. Given (25), it follows that $\eta^{*}<1$ if and only if

$$
E\left(\frac{\beta}{\theta}\right)>1
$$

The following proposition summarizes the result.

Proposition 1 A balanced growth equilibrium with bubbles exists if and only if (41) holds.

Note that condition (41) is likely to be satisfied when the variance of $\theta$ is 
large. In this sense, our result implies that bubbles are likely to emerge when individuals face a large amount of uninsurable risk to their 'savings'. We would like to emphasize that our concept of capital, $K$, can include human capital, not just physical capital. It is well known that the accumulation of human capital is subject to a significant amount of risk (see, for example PalaciosHuerta (2003)), which is largely idiosyncratic and uninsurable.

As in previous models of rational bubbles, our condition for the existence of bubbles can also be stated in terms of the growth rate, $\hat{G}$, and the interest rate, $\hat{R}$, that would prevail in the equilibrium without bubbles. It immediately follows from equations (13) and (15) that condition (41) is equivalent to $\hat{G}>\hat{R}$. Note that the average rate of retun of investment is $A>1$, so the economy is dynamically efficient in the sense of Abel et al. (1989). However, because idiosyncratic risk is uninsurable, the interest rate $\hat{R}$ is less than the growth rate of the economy. This mechanism behind the low interest rate is different from that of the recent literature on rational bubbles that relies on the existence of credit frictions (Farhi and Tirole (2012), Martin and Ventura (2012), Aoki and Nikolov (2012), Hirano and Yanagawa (2010)). In those papers, credit frictions prevent savings from flowing to the most productive use, depressing equilibrium interest rates. In our model, it is uninsurable idiosyncratic risk that depresses the equilibrium interest rate.

Proposition 2 Let $\hat{G}$ and $\hat{R}$ denote the growth rate and the interest rate in the equilibrium without bubbles. A balanced growth equilibrium with bubbles exists if and only if $\hat{G}>\hat{R}$.

If there were no idiosyncratic risk so that $\theta=1$ almost surely, then the real interest rate is necessarily larger than the growth rate, $\hat{R}=A>\beta A=\hat{G}$, and there is no room for bubbles. As the variance of $\theta$ increases, individuals 
are subject to more risk and the safe real interest rate falls. This can be seen from a second order Taylor expansion of (15):

$$
\hat{R} \approx \frac{A}{1+\operatorname{var}(\theta)}
$$

When the idiosyncratic risk is sufficiently large, the safe real interest rate becomes lower than the economic growth rate in the absence of bubbles $(\beta A)$, which creates room for rational bubbles:

$$
\frac{A}{1+\operatorname{var}(\theta)}<\beta A
$$

It can be easily confirmed that condition (43) is exactly what we obtain from a Taylor expansion of (41). Intuitively, the bubble must be attractive to hold while being aymptotically stable as a share of output. Since the economy's growth rate $(\beta A)$ is lower than the expected return on production $(A)$, productive assets must be held with a substantial risk premium if the safe bubble can be both attractive and asymptotically non-explosive. Equation (43) states that the gross risk-premium on production (approximately equal to $1+\operatorname{var}(\theta)$ ) must be large enough so as to ensure that the return on the safe bubble (the risk free rate $\hat{R}$ given by (42)) is lower than the economy's growth rate.

Proposition 3 The bubble is contractionary. It reduces the economy's growth rate.

To see that the bubble is contractionary, it is sufficient to show that $G^{*}$ is increasing in $\eta$ (the share of productive projects in household portfolios). Hence, as the share of bubbles in wealth grows (and $\eta$ declines), growth declines. It 
is easy to verify that this is the case.

$$
\frac{\partial G^{*}}{\partial \eta}=\frac{(1-\beta) \beta A}{1-\beta(1-\eta)}>0
$$

Ours is a model without credit constraints and consequently the bubble does not help to expand economic activity by relaxing financial frictions. Instead, its impact on growth in our AK-model framework arises due to the way it affects the investment rate in equilibrium. Our model has an expansionary wealth effect and a contractionary portfolio crowding out effect. From equation (36) the bubble increases wealth and this in turn increases total saving, investment and economic growth. But because bubbles take up a part of household portfolios $(\eta<1)$ they also crowd out investment in productive assets and this retards economic growth.

Proposition 3 shows that the contractionary effect always dominates when $\beta<1$. This is because the presence of the bubble raises consumption and leads to a 'wealth leakage'. This can be seen from equation (35): the level of consumption increases at least temporarily when a bubble pops up because the wealth of each individual increases. ${ }^{7}$ Because $1-\beta$ fraction of the additional bubble wealth is consumed, the wealth-creating effect of the bubble is always smaller than its crowding out effect. As a result, the investment rate and the consumption growth rate decline even if the level of consumption can temporarily increase due to the wealth effect of the bubble.

We can see this very clearly when we consider the case when $\beta \approx 1$ and the marginal propensity to consume out of wealth is negligible. Then $G^{*} \approx A$ and the economy's growth rate is independent of household portfolios in the

\footnotetext{
${ }^{7}$ For example, when the bubble shows up at time 0 , the wealth level jumps up from $A K_{-1}$ to $A K_{-1}+\mu_{0}$
} 
bubbly equilibrium. In this case (38) implies that

$$
\mu_{t} \approx \frac{1-\eta}{\eta} A K_{t-1}
$$

and so from (36), the wealth creating effect of the bubble exactly offsets the contractionary impact of bubble holdings, leaving investment and growth unchanged. As $\beta$ declines below unity, consumption out of the bubble wealth ensures that the contractionary impact of bubbles dominates.

The negative growth impact of the bubble is in contrast to the results in several recent papers that add credit frictions (for example Martin and Ventura (2012) and Hirano and Yanagawa (2010)) who find that bubbles may, under certain conditions, increase economic growth. In Hirano and Yanagawa (2010)), bubbles have both growth enhancing and growth reducing effects. On the one hand, when the bubble shows up, agents divert part of savings from physical investment to bubble holdings, similarly to what happens in our model. This reduces the rate of economic growth. On the other hand, the bubble increases the net worth of credit-constrained entrepreneurs, allowing them to invest more. This effect increases the rate of economic growth. Hirano and Yanagawa (2010) show that the second effect dominates when the borrowing constraint is tight enough.

Our main interest is in the way a shortage of safe assets may affect the existence conditions for bubbles and, consequently, we assume no borrowing constraints. Therefore, our result on the economic growth rate is similar to that of Hirano and Yanagawa (2010) when the borrowing constraint is mild (so that the growth enhancing effect is smaller).

Miao and Wang (2014) construct a two sector endogenous growth model to analyse the impact of bubbles on economic growth. They show that when a 
bubble occurs in the sector with positive externalities, it may increase economic growth. However, when the bubble occurs in the sector with no externality, it may reduce economic growth. Since our model features no externalities, our results are in line with Miao and Wang (2014)'s case of bubbles attached to the sector that generates no growth-inducing spillovers.

\subsection{Numerical example: uniform distribution}

To help build intuition about the properties of our model, here we consider an example where $\theta$ follows uniform distribution on $[1-\epsilon, 1+\epsilon]$ with $0<\epsilon<1$. We shall derive an explicit condition on $\epsilon$ for the existence of bubbles and then demonstrate some comparative statics with respect to the extent of production risk $(\epsilon)$.

\subsubsection{Bubble existence conditions}

When $\theta$ follows a uniform distribution on $[1-\epsilon, 1+\epsilon]$ with $0<\epsilon<1$, equation (41) is equivalent to

$$
\frac{\beta}{2 \epsilon} \ln \left(\frac{1+\epsilon}{1-\epsilon}\right)>1
$$

In terms of $\hat{G}$ and $\hat{R},(46)$ is equivalent to

$$
\hat{G}=\beta A>\left[\frac{1}{A} \frac{1}{2 \epsilon} \ln \left(\frac{1+\epsilon}{1-\epsilon}\right)\right]^{-1}=\hat{R}
$$

To illustrate the model properties we parameterise the model ${ }^{8}$ and show how several endogenous variables depend on the riskiness of the production $(\epsilon)$. Figure 1 plots $\hat{G}$ and $\hat{R}$ as a function of $\epsilon$. The figure shows that when $\epsilon$ is large enough (investment is risky enough) then the bubbly equilibrium exists.

\footnotetext{
${ }^{8}$ The parameter values we use are $\beta=0.95, A=1.1$. We vary $\epsilon$ in order to generate the model's comparative statics. The exercise should be viewed as a numerical illustration of the model properties rather than as a quantitative application.
} 
[Figure 1 here]

\subsubsection{Comparative statics with respect to $\epsilon$}

Figure 2 plots the share of the bubble asset in household portfolios $(1-\eta)$ as a function of $\epsilon$.

[Figure 2 here]

Figure 2 shows that as the investment project becomes riskier the individuals invest a greater share of their wealth in the bubble.

Figure 3 shows how the economy's growth rate changes with $\epsilon$ both with and without bubbles. The figure shows that the bubble is increasingly contractionary at higher levels of idiosyncratic investment risk. This is because the bubble crowds out investment.

[Figure 3 here]

To get a clear idea of the trade-offs that determine the size of the bubble we also plot in Figure 4 the consumption growth standard deviation both with and without bubbles together with the standard deviation of the idiosyncratic TFP shock.

[Figure 4 here]

The figure shows that in the absence of bubbles, higher shock volatility translates directly into higher consumption volatility. In the bubbly equilibrium of our economy, however, this is not the case. Higher shock volatility does lead to more volatile consumption growth but the expansion of the bubble moderates this increase at the expense of a reduced economic growth rate. 


\subsection{Welfare effect of bubbles}

We have seen that bubbles circulate when markets for insuring idiosyncratic shocks are missing. And we have also seen that bubbles are detrimental to economic growth. But do bubbles increase welfare? And how does welfare in the bubbly equilibrium compare to the first best with complete markets?

In this subsection we compare in welfare terms (i) the equilibrium without bubbles considered in section 2; (ii) the (balanced growth) equilibrium with bubbles in section 3.2; and (iii) the equilibrium with complete markets. To do so, we fix the initial wealth distribution $\left\{y_{0}^{i}\right\}_{i \in[0,1]}$, where $y_{0}^{i}=\theta_{0}^{i} A k_{-1}^{i}>0$ for $i \in[0,1]$. The implied initial aggregate capital stock is $K_{-1}=\int_{0}^{1} k_{-1}^{i} d i$.

\subsubsection{Welfare comparison between the bubbly and bubbleless equi- libria}

First consider the equilibrium without bubbles. Let $V^{N B}(y)$ denote the lifetime utility of an individual with initial condition $y_{0}^{i}=y$. As shown in equation (A.9) in Appendix A, in the equilibrium without bubbles, it is given as

$$
V^{N B}(y)=\frac{1}{1-\beta}\left\{\ln (1-\beta)+\frac{\beta \ln \beta}{1-\beta}+\frac{\beta}{1-\beta} E[\ln (\theta A)]+\ln (y)\right\} .
$$

Now consider the balanced growth equilibrium with bubbles. Consider an arbitrary initial distribution of the bubble asset $\left\{m_{-1}^{i}\right\}_{i \in[0,1]}$, where $m_{-1}^{i} \geq 0$

for all $i$ and $\int_{0}^{1} m_{-1}^{i} d i=1$. It follows from equation (38) that the price of the bubble, $\mu_{0}$, in period 0 is

$$
\mu_{0}=\frac{\beta\left(1-\eta^{*}\right)}{1-\beta\left(1-\eta^{*}\right)} A K_{-1}
$$

where $\eta^{*} \in(0,1)$ is the solution to $(23)$ under the balanced growth path. The 
initial wealth of individual $i \in[0,1]$ is then equal to $w_{0}^{i} \equiv y_{0}^{i}+\mu_{0} m_{-1}^{i}$. It follows from (26)-(28) that, along the balanced growth path, the level of individual wealth, $w_{t}^{i}=y_{t}^{i}+\mu_{t} m_{t-1}^{i}$, evolves as

$$
w_{t+1}^{i}=\beta R\left(\theta_{t+1}^{i}\right) w_{t}^{i}
$$

Here $R\left(\theta_{t+1}^{i}\right)$ is defined as

$$
\begin{aligned}
R(\theta) & \equiv \eta^{*} \theta A+\left(1-\eta^{*}\right) R^{*} \\
& =\eta^{*} A\left\{\theta+\frac{\left(1-\eta^{*}\right) \beta}{1-\beta\left(1-\eta^{*}\right)}\right\},
\end{aligned}
$$

where the second equality has the fact that, in the bubbly equilibrium, the growth rate of the bubble $\left(R^{*}\right)$ is equal to the growth rate of output:

$$
R^{*}=\frac{\beta \eta^{*} A}{1-\beta\left(1-\eta^{*}\right)}
$$

Let $V^{B}(w)$ denote the lifetime utility of an individual with initial wealth $w$, which, along the balanced growth equilibrium, is computed as

$$
V^{B}(w)=\frac{1}{1-\beta}\left\{\ln (1-\beta)+\frac{\beta \ln \beta}{1-\beta}+\frac{\beta}{1-\beta} E[\ln (R(\theta))]+\ln (w)\right\} .
$$

Given the initial distribution $\left\{y_{0}^{i}, m_{-1}^{i}\right\}_{i \in[0,1]}$, we compare the lifetime utility (48) and (53) for each individual. Note that the definition of $\eta^{*}$ implies that $E[\ln (R(\theta))]>E[\ln (A \theta)]$. It follows that

$$
\begin{aligned}
& V^{B}\left(y_{0}^{i}+\mu_{0} m_{-1}^{i}\right)-V^{N B}\left(y_{0}^{i}\right) \\
& \quad=\frac{\beta}{(1-\beta)^{2}}\{E[\ln (R(\theta))]-E \ln (A \theta)\}+\frac{1}{1-\beta}\left\{\ln \left(y_{0}^{i}+\mu_{0} m_{-1}^{i}\right)-\ln \left(y_{0}^{i}\right)\right\} \\
& \quad>0 .
\end{aligned}
$$


Thus bubbles are Pareto improving in our model. The next proposition summarizes the result.

Proposition 4 Assume (41) holds so that the balanced growth equilibrium with bubbles exists. Given an arbitrary initial distribution of output and the bubble asset, $\left\{y_{0}^{i}, m_{-1}^{i}\right\}_{i \in[0,1]}$, consider balanced growth equilibria with and without bubbles. Then the lifetime utility is greater in the equilibrium with bubbles for all individuals $i \in[0,1]$ :

$$
V^{B}\left(y_{0}^{i}+\mu_{0} m_{-1}^{i}\right) \geq V^{N B}\left(y_{0}^{i}\right), \quad \forall i \in[0,1]
$$

In our model bubbles decrease growth but unambiguously increase welfare. There are three offsetting effects. Firstly, bubbles help consumption smoothing across different states of nature when insurance markets are missing. This insurance effect increases welfare. Secondly, lower consumption growth reduces welfare. Thirdly, as discussed in Section 3.2, even though the emergence of bubbles decreases the rate of consumption growth, it can increase the level of consumption in the short run because of its wealth effect (see equation (35)).

To see this more clearly, note first that expected utility can be written as follows:

$$
\sum_{t=0}^{\infty} \beta^{t} \ln \left(c_{t}\right)=\frac{1}{1-\beta} \ln \left(c_{0}\right)+\frac{\beta}{1-\beta} \sum_{t=0}^{\infty} \beta^{t} \ln \left(\frac{c_{t+1}}{c_{t}}\right) .
$$

Thus, the expected utility is decomposed into the three terms discussed above:

$$
\begin{aligned}
E_{0} \sum_{t=0}^{\infty} \beta^{t} \ln \left(c_{t}\right)= & \frac{1}{1-\beta} \ln \left(c_{0}\right) \\
& +\frac{\beta}{1-\beta} \sum_{t=0}^{\infty} \beta^{t} \ln \left(E_{0}\left[\frac{c_{t+1}}{c_{t}}\right]\right) \\
& +\frac{\beta}{1-\beta} \sum_{t=0}^{\infty} \beta^{t}\left\{E_{0}\left[\ln \left(\frac{c_{t+1}}{c_{t}}\right)\right]-\ln \left(E_{0}\left[\frac{c_{t+1}}{c_{t}}\right]\right)\right\}
\end{aligned}
$$


where the first term represents the 'level effect,' the second term the 'growth effect,' and the last term the 'insurance effect.' Note that the insurance effect is negative because of Jensen's inequality, and becomes zero with perfect insurance $^{9}$. Now consider individual $i$ with initial assets $\left(y_{0}^{i}, m_{-1}^{i}\right)$. Let $\left\{c_{t}^{* i}\right\}_{t=0}^{\infty}$ and $\left\{\hat{c}_{t}^{i}\right\}_{t=0}^{\infty}$ denote, respectively, her equilibrium consumption processes in the equilibria with and without bubbles. Then we have

$$
\begin{aligned}
c_{0}^{* i} & =(1-\beta)\left(y_{0}^{i}+\mu_{0} m_{-1}^{i}\right), \\
\hat{c}_{0}^{i} & =(1-\beta) y_{0}^{i}, \\
\frac{c_{t+1}^{* i}}{c_{t}^{* i}} & =\beta R\left(\theta_{t+1}^{i}\right), \\
\frac{\hat{c}_{t+1}^{i}}{\hat{c}_{t}^{i}} & =\beta A \theta_{t+1}^{i} .
\end{aligned}
$$

Remember that $E[\beta R(\theta)]=G^{*}$ and $E[\beta A \theta]=\hat{G}$. Together with (57), these equations can be used to decompose the lifetime utility of individual $i$ in the equilibrium with bubbles as:

$$
\begin{aligned}
V^{B}\left(y_{0}^{i}+\mu_{0} m_{-1}^{i}\right)= & \frac{1}{1-\beta} \ln \left(c_{0}^{* i}\right)+\frac{\beta}{(1-\beta)^{2}} \ln \left(G^{*}\right) \\
& +\frac{\beta}{(1-\beta)^{2}}\left\{E[\ln (\beta R(\theta))]-\ln \left(G^{*}\right)\right\},
\end{aligned}
$$

where the three terms correspond to the level, growth, and insurance effects, respectively. A similar decomposition is obtained for her lifetime utility for the equilibrium without bubbles. Then the welfare gain of bubbles (54) is

\footnotetext{
${ }^{9}$ The insurance effect takes the minimum value of zero because there is no aggregate uncertainty.
} 
rewritten as

$$
\begin{aligned}
& V^{B}\left(y_{0}^{i}+\mu_{0} m_{-1}^{i}\right)-V^{N B}\left(y_{0}^{i}\right) \\
& \quad=\frac{1}{1-\beta}\left\{\ln \left(c_{0}^{* i}\right)-\ln \left(\hat{c}_{0}^{i}\right)\right\}+\frac{\beta}{(1-\beta)^{2}}\left\{\ln \left(G^{*}\right)-\ln (\hat{G})\right\} \\
& \quad+\frac{\beta}{(1-\beta)^{2}}\left\{\left(E[\ln (\beta R(\theta))]-\ln \left(G^{*}\right)\right)-(E[\ln (\beta A \theta)]-\ln (\hat{G}))\right\},
\end{aligned}
$$

where the first term, the level effect, is non-negative, the second term, the growth effect, is negative, and the third term, the insurance effect, is positive. Note that the insurance effect is large enough that even without the level effect the welfare gain of bubbles is strictly positive. To see this, set $m_{-1}^{i}=0$ so that $c_{0}^{* i}=\hat{c}_{0}^{i}$, and

$$
V^{B}\left(y_{0}^{i}+\mu_{0} m_{-1}^{i}\right)-V^{N B}\left(y_{0}^{i}\right)=\frac{\beta}{(1-\beta)^{2}}\{E[\ln (\beta R(\theta))]-E[\ln (\beta A \theta)]\}>0 .
$$

In this sense, the critical factor for the welfare gain of bubbles is the insurance effect. Although bubbles reduce the expected growth rate, they provide better insurance against idiosyncratic risks so that everyone, including even those who do not possess bubbles initially, becomes better off.

One may wonder whether the benefit of consumption smoothing is large enough to offset the level effect of slower economic growth. Indeed, Lucas (1987) shows that the cost of business cycle is small because aggregate consumption is not very volatile. Note that in our model bubbles help to smooth consumption in the face of idiosyncratic risk $^{10}$ which has been shown empirically to be much larger than aggregate risk ${ }^{11}$. Since idiosyncratic risk is very

\footnotetext{
${ }^{10}$ Indeed, aggregate consumption does not fluctuate stochastically in our basic framework with and without bubbles as long as bubbles are safe.

${ }^{11}$ See, for example, Meghir and Pistaferri (2004). They show that the variance of the permanent shock to individual income is about 0.0313 , which means that its standard deviation is more than $17 \%$.
} 
large, the welfare gain from reducing its impact on consumption volatility can be very sizable.

Our result is in contrast to that of Grossman and Yanagawa (1993) who show that bubbles can decrease both growth and the welfare of some agents. The reason for this difference lies in the presence of capital externalities in the Grossman and Yanagawa (1993) model. Both our model and theirs feature an aggregate AK technology. In Grossman and Yanagawa (1993), however, individual firms have decreasing private returns to capital and the aggregate production function is linear in capital only due to production externalities. As a result, in their model, a situation may arise in which the interest rate (which reflects the private return on capital) is lower than the rate of economic growth even though investment is dynamically efficient from a social point of view. Then bubbles crowd out efficient capital investment and reduce welfare.

Our framework features a similar cost of bubbles. Since all production is dynamically efficient in the sense of Abel et al. (1989), the growth reducing impact of bubbles is a tangible cost. However, because bubbles allow a smoother consumption profile, they also provide a benefit to the economy ${ }^{12}$. In our framework, agents are infinitely lived and there are no externalities, and as a result, private and social optimality coincide, in contrast to Grossman and Yanagawa (1993). Therefore bubbles exist only when the consumption smoothing benefit outweighs the growth-reduction cost of bubbles as shown in Proposition 4. For this reason bubbles are always welfare improving in our model.

Our result is more in line with Hirano and Yanagawa (2010). They show that bubbles reduce the rate of economic growth when the degree of credit friction is intermediate (but increases the rate of economic growth when credit

\footnotetext{
${ }^{12}$ There is no such benefit from bubbles in Grossman and Yanagawa (1993).
} 
frictions are severe enough). However, welfare unambiguously increases in their model too regardless of what happens to economic growth. This is because bubbles help consumption smoothing over time by smoothing the rate of return on wealth earned by different agents ${ }^{13}$. In our framework, there are no credit constraints and therefore consumption smoothing over time is not distorted. Bubbles instead improve consumption smoothing over different states of nature, helping to correct the distortion caused by missing markets for insuring idiosyncratic risk.

\subsubsection{Welfare comparison between the bubbly equilibrium and the first best}

Now consider the equilibrium with complete markets. Suppose that there exists a complete insurance markets for individual risks $\theta_{t}^{i}$ for all $i$ and $t$. Here we allow the social planner to redistribute initial output: let $\left\{z_{0}^{i}\right\}_{i \in[0,1]}$ denote the distribution of output after the redistribution, that is, $z_{0}^{i}>0$ for all $i$ and $\int_{0}^{1} z_{0}^{i} d i=A K_{-1}$. Then we shall show that given any distribution of the bubble asset, $\left\{m_{-1}^{i}\right\}_{i \in[0,1]}$, there exists a redistribution of output, $\left\{z_{0}^{i}\right\}_{i \in[0,1]}$, so that all individuals are better off in the equilibrium with complete markets than in the equilibrium with bubbles. Redistribution of output may occur only in period 0 , and no more interventions are made thereafter.

It is straightforward to show that in the complete-markets equilibrium

$$
c_{t}^{i}=(1-\beta)(\beta A)^{t} z_{0}^{i},
$$

for all $i$ and $t$. It follows that the lifetime utility of each individual under

\footnotetext{
${ }^{13}$ In their model, agents' investment productivity switches between high and low levels stochastically. Bubbles increase the rate of return on wealth of agents with low productivity because they are the ones who invest in bubbles. In their bubbly equilibrium the rates of return on savings are smoothed over time and thus consumption becomes smoother.
} 
complete markets, denoted by $V^{C M}\left(z_{0}^{i}\right)$, is

$$
V^{C M}\left(z_{0}^{i}\right)=\frac{1}{1-\beta}\left\{\ln (1-\beta)+\frac{\beta \ln \beta}{1-\beta}+\frac{\beta}{1-\beta} \ln (A)+\ln \left(z_{0}^{i}\right)\right\} .
$$

Consider the bubble equilibrium corresponding to an arbitrary initial distribution $\left\{y_{0}^{i}, m_{-1}^{i}\right\}_{i \in[0,1]}$. For the complete-markets equilibrium, consider the redistribution of output as:

$$
z_{0}^{i}=\left(1-\beta+\beta \eta^{*}\right)\left(y_{0}^{i}+\mu_{0} m_{-1}^{i}\right), \quad \forall i \in[0,1]
$$

Such a redistribution is feasible because, given $\mu_{0}$ in (49), we have

$$
\int_{0}^{1}\left(y_{0}^{i}+\mu_{0} m_{-1}^{i}\right) d i=\frac{1}{1-\beta\left(1-\eta^{*}\right)} A K_{-1}
$$

Then, as we show in Appendix B,

$$
V^{C M}\left(z_{0}^{i}\right)-V^{B}\left(y_{0}^{i}+\mu_{0} m_{-1}^{i}\right)>0 .
$$

It follows that given the redistributed output $\left\{z_{0}^{i}\right\}_{i \in[0,1]}$, all individuals are better off in the equilibrium with complete markets than in the one with bubbles. The following proposition summarizes the result.

Proposition 5 Assume (41) holds so that the balanced growth equilibrium with bubbles exists. For any initial distribution of output and the bubble asset, $\left\{y_{0}^{i}, m_{-1}^{i}\right\}_{i \in[0,1]}$, there exists a redistribution of output $\left\{z_{0}^{i}\right\}_{i \in[0,1]}$ such that all individuals have higher lifetime utility in the equilibrium with complete markets than in the one with bubbles.

$$
V^{C M}\left(z_{0}^{i}\right)>V^{B}\left(y_{0}^{i}+\mu_{0} m_{-1}^{i}\right), \quad \forall i \in[0,1] .
$$


In our framework, the first best allocation involves households investing their entire wealth in productive assets (since these are dynamically efficient in the sense of Abel et al. (1989)) but pooling idiosyncratic investment risk in order to achieve a riskless consumption allocation. Growth will be the same as in the bubbleless equilibrium $(\beta A)$ but utility will be higher due to the gains from consumption smoothing.

As we showed in Proposition 4, conditional upon the absence of markets that can pool idiosyncratic production risk, the bubble is welfare improving because it helps to smooth consumption. However the crowding out effect from bubble holdings is a cost associated with the improvement in consumption risk sharing. Then the result in Proposition 5 intuitively follows: welfare in the bubbly equilibrium is strictly lower than in the first best.

\section{Stochastic bubbles}

In this section we consider stochastic bubbles. For simplicity, we restrict our attention to a particular class of such bubbles that is commonly studied in the literature. Specifically, we consider the following class of stochastic bubbles: (i) once it bursts, the bubble asset will never have a positive value again; (ii) if the bubble asset has a positive value in period $t$, the gross rate of return of the bubble asset between periods $t$ and $t+1, \tilde{R}_{t+1}$, is given by

$$
\tilde{R}_{t+1}= \begin{cases}R & \text { with probability } \pi \\ 0 & \text { with probability } 1-\pi\end{cases}
$$

Thus, $\tilde{R}_{t+1}$ is i.i.d., and hence we occasionally omit the time subscript. We also assume that $\tilde{R}_{t+1}$ is independent of idiosyncratic shocks $\theta_{s}^{i}$ for all $s$ and $i$. Let $\mu_{t}$ denote the value of the bubble asset in period $t$ conditional on the 
fact that the bubble has not burst yet: $\mu_{t}=R^{t} \mu_{0}$. In what follows, we take $\pi$ as a given parameter and determine $R$ as an endogenous variable that is determined in equilibrium.

The utility maximization problem for each individual can be solved in an almost identical way as in the previous section. Define $\eta \in[0,1]$ by

$$
\eta=\underset{\eta \in[0,1]}{\arg \max } E_{t}\left[\ln \left[\theta A \eta+\tilde{R}_{t+1}(1-\eta)\right]\right]
$$

Since $\tilde{R}_{t+1}$ is i.i.d., $\eta$ does not depend on time. Given $\eta$ thus defined, the solution to the utility maximization problem remains to be given by (26)-(28).

The first-order condition for the interior solution $\eta \in(0,1)$ is

$$
E\left[\frac{\theta A-\tilde{R}}{\theta A \eta+\tilde{R}(1-\eta)}\right]=\pi E\left[\frac{\theta A-R}{\theta A \eta+R(1-\eta)}\right]+(1-\pi) \frac{1}{\eta}=0 .
$$

As in the previous section, $\eta>0$ is always satisfied. Given $R$, the condition that guarantees $\eta<1$ is now given by

$$
\pi E\left(\frac{R}{\theta A}\right)>1
$$

By aggregating the solution to the individual utility maximization problem, we obtain

$$
R=\frac{\mu_{t+1}}{\mu_{t}}=\frac{\beta \eta}{1-\beta(1-\eta)} A
$$

and

$$
\tilde{G} \equiv \frac{K_{t+1}}{K_{t}}= \begin{cases}\frac{\beta \eta}{1-\beta(1-\eta)} A & \text { with probability } \pi \\ \beta \eta A & \text { with probability } 1-\pi\end{cases}
$$

Note that $\tilde{G}=\tilde{R}$ when bubbles survive.

It is straightforward to show that the necessary and sufficient condition for 
the existence of the type of stochastic bubbles considered here is

$$
\pi E\left(\frac{\beta}{\theta}\right)>1
$$

Clearly, a necessary condition for the existence of stochastic bubbles is that bubbles are safer than capital, that is, the rate of return on bubbles has smaller variance than that on capital. To see this, note first that the expected rate of return of bubbles is smaller than that of capital:

$$
E[\tilde{R}]=\pi R=\frac{\pi \beta \eta}{1-\beta+\beta \eta} A<A=E[\theta A]
$$

Second, returns on bubbles and capital are independent by construction. It follows that a risk-averse individual never holds bubbles if their return has larger variance than that of capital. Equation (73) provides the exact bound on how risky bubbles can be.

The intuition for (73) can again be obtained from considering the approximate arbitrage condition for the rate of return on bubbles when bubble holdings are approximately zero (i.e. when $\eta \approx 1$ ). In this case, the risk-free rate is given by (15) which can be approximated as:

$$
\hat{R} \approx \frac{A}{1+\operatorname{var}(\theta)}
$$

When $\eta \approx 1$ consumption is approximately independent of the bubble return and consequently, the arbitrage condition between bubbles and risk free assets can be approximated by an equalisation in the expected returns. Then the 
return of the bubble conditional upon the bubble surviving is given by:

$$
\begin{aligned}
\frac{\mu_{t+1}}{\mu_{t}} & \approx \frac{\hat{R}}{\pi} \\
& \approx \frac{A}{\pi(1+\operatorname{var}(\theta))} .
\end{aligned}
$$

In equilibrium this return must not exceed the economy's growth rate if the bubble is to be sustainable in the long run. In other words

$$
\frac{A}{\pi(1+\operatorname{var}(\theta))}<\beta A
$$

It can easily be confirmed that (77) can be obtained from a second order Taylor expansion of (73).

The bubble existence condition (77) is dominated by two factors. The first factor is the relative riskiness of the stochastic bubble and the risky productive project as measured by the $\frac{1}{\pi(1+\operatorname{var}(\theta))}$ ratio. This is the ratio of the gross excess return on bubbles conditional upon bubble survival (approximately equal to $1 / \pi^{14}$ ) to the risk premium on production (approximately equal to $1+\operatorname{var}(\theta)$ ). When $\beta \approx 1$, condition (77) simplifies to:

$$
\frac{1}{\pi}<1+\operatorname{var}(\theta)
$$

In other words, the risk premium on the bubble must be smaller than the risk premium on production. This is intuitive since the role of the bubble is to act as a safe asset and help consumption smoothing. Hence its rate of return must be safer than the rate of return on production.

\footnotetext{
${ }^{14}$ This is not a 'risk premium' in the sense of a higher expected return on the bubble. Equation (76) states that the bubble yields approximately the same expected return as the risk-free rate. However, even in this approximately risk-neutral world, the bubble must grow faster conditional on survival when its probability of bursting and becoming worthless $(1-\pi)$ is higher.
} 
The second important factor in condition (77) is the $\beta$ term which reflects the impact of consumption on economic growth. When $\beta<1$, the economy's growth rate is below the return of the risky technology and this tightens the condition for bubble condition (since the return on the bubble must be at or below the economy's growth rate). This implies that as $\beta$ declines, bubbles exist only when they are safer ( $\pi$ is higher) or when production is riskier $(\operatorname{var}(\theta)$ is higher).

If $\theta$ is uniformly distributed on $[1-\epsilon, 1+\epsilon],(73)$ becomes

$$
\frac{\pi \beta}{2 \epsilon} \ln \left(\frac{1+\epsilon}{1-\epsilon}\right)>1
$$

It is easy to verify that in this example bubbles exist as long as idiosyncratic production risk and the bubble's survival probability $(\pi)$ are both large enough.

\section{Conclusion}

We construct a model economy which features bubbly equilibria driven by a shortage of safe assets. Agents face uninsurable idiosyncratic production risk which in turn creates considerable idiosyncratic consumption risk. When production uncertainty is high enough, real interest rates on safe bonds decline below the growth rate of the economy, opening the possibility that safe bubbles can circulate and provide consumers with the safe asset they need in order to smooth consumption.

When they exist, bubbles reduce economic growth by crowding out risky production. Lower growth is the price the economy has to pay in order to reduce the consumption volatility associated with idiosyncratic production uncertainty.

Bubbles affect welfare through three channels. Firstly, they reduce growth 
which is welfare-reducing. Secondly, the wealth effect of the bubbles increases the level of consumption, at least in the short run. Thirdly, and most importantly, the bubbles allow households to smooth consumption better. The last two effects increase welfare but we show that the third (consumption smoothing) effect is crucial and, as a result, the bubbles are always welfare improving when they exist in our model. This finding is very relevant in the current environment where a decline in investor confidence in bank deposits and Southern European government debt has led to the sharp appreciation of the prices of other 'safe' assets such as prime real estate and US/German government debt. Our paper suggests that this may be welfare improving and not a phenomenon which policy should necessarily attempt to counter.

Our results also show that asset price bubbles are not a perfect substitute for complete financial markets. Even though the safe bubble in our model is welfare improving, the value of all bubbles depends on investor sentiment and therefore can never be completely safe. Hence, one important policy goal for governments is to promote financial development and, in particular, the development of markets which allow the hedging of the very high degree of idiosyncratic risk to which individuals are exposed to. This will remove the conditions for bubble existence but will be welfare improving in our model framework. Another policy goal would be to provide enough high-quality safe assets (government bonds) so that agents can self-insure without relying on the bubble.

\section{Appendix A The household value function}

In this Appendix we solve for the value function of the household by a 'guess and verify' method. We guess that the value function of a household with 
wealth $w_{t}$ is of the following form:

$$
V\left(w_{t}\right)=\phi_{t}^{0}+\phi_{t}^{1} \ln w_{t}
$$

Setting up the value function in terms of the maximum of current and future utility we have:

$$
V\left(w_{t}\right)=\max _{c_{t}, \eta_{t}}\left\{\ln c_{t}+\beta E_{t} V\left(w_{t+1}\right)\right\}
$$

where the expectation operator $E_{t}$ is taken with respect to distribution of the idiosyncratic productivity shocks $\theta$ as well as the sunspot shocks which determine whether the bubble collapses or not. When the household invests $\eta_{t}$ of its savings in production, its wealth evolves as follows:

$$
w_{t+1}=\left\{\theta A \eta_{t}+R\left(1-\eta_{t}\right)\right\} \beta w_{t}
$$

Using the fact that, under log utility, consumption is a fixed fraction of wealth and using our value function guess, we can rewrite (A.2) as:

$$
\begin{aligned}
& \phi_{t}^{0}+\phi_{t}^{1} \ln w_{t} \\
= & \ln (1-\beta)+\ln w_{t}+\beta \max _{\eta_{t}} E_{t}\left[\phi_{t+1}^{0}+\phi_{t+1}^{1}\left\{\ln \left(\theta A \eta_{t}+R\left(1-\eta_{t}\right)\right)+\ln \beta+\ln w_{t}\right\}\right] .
\end{aligned}
$$

Equating coefficients on the $\ln w_{t}$ terms, we get a functional equation for $\phi_{t}^{1}$ :

$$
\phi_{t}^{1}=1+\beta E_{t} \phi_{t+1}^{1}
$$

It is easy to see that the slope of the value function $\left(\phi_{t}^{1}\right)$ will actually be time-invariant and equal to:

$$
\phi_{t}^{1}=\frac{1}{1-\beta} .
$$


Equating the intercept terms we get a functional equation in $\phi_{t}^{0}$ :

$$
\phi_{t}^{0}=\ln (1-\beta)+\frac{\beta \ln \beta}{1-\beta}+\frac{\beta}{1-\beta} \max _{\eta_{t}} E_{t}\left[\ln \left(\theta A \eta_{t}+R\left(1-\eta_{t}\right)\right)\right]+\beta E_{t} \phi_{t+1}^{0} .
$$

In general, $\phi_{t}^{0}$ will vary over time in response to shocks. In the paper we focus on the stochastic steady state: this is the steady state to which the economy converges after a long time in which the stochastic bubble has not burst. In the stochastic bubbly steady state, $\phi_{t}^{0}$ will be time invariant and equal to:

$$
\phi_{t}^{0}=\frac{1}{1-\beta}\left\{\ln (1-\beta)+\frac{\beta \ln \beta}{1-\beta}+\frac{\beta}{1-\beta} \max _{\eta} E_{t}[\ln (\theta A \eta+R(1-\eta))]\right\} .
$$

Hence, in the stochastic bubbly steady state, the household value function becomes:

$$
V^{s s}=\frac{1}{1-\beta}\left\{\ln (1-\beta)+\frac{\beta \ln \beta}{1-\beta}+\frac{\beta}{1-\beta} \max _{\eta} E_{t}[\ln (\theta A \eta+R(1-\eta))]+\ln w^{s s}\right\}
$$

\section{Appendix B Welfare gain from complete mar- kets}

We have defined the redistributed output $\left\{z_{0}^{i}\right\}_{i \in[0,1]}$ so as to ensure that the initial wealth of any agent in the complete markets is proportional to his/her initial wealth in the bubbly equilibrium. Let $V^{C M}$ be the expected life-time utility of agent $i$ under complete markets after redistribution, and $V^{B}$ be his 
expected life-time utility in the bubbly equilibrium. Then

$$
\begin{aligned}
V^{C M} & \left(z_{0}^{i}\right)-V^{B}\left(y_{0}^{i}+\mu_{0} m_{-1}^{i}\right) \\
& =\frac{1}{1-\beta}\left\{\frac{\beta}{1-\beta} \ln (A)+\ln \left(1-\beta+\beta \eta^{*}\right)-\frac{\beta}{1-\beta} E[\ln (R(\theta))]\right\} .
\end{aligned}
$$

Since $E[\ln (R(\theta))]<\ln \frac{A \eta^{*}}{1-\beta+\beta \eta^{*}}$, it follows from Jensen's Inequality that

$$
\begin{aligned}
& V^{C M}\left(z_{0}^{i}\right)-V^{B}\left(y_{0}^{i}+\mu_{0} m_{-1}^{i}\right) \\
> & \frac{1}{1-\beta}\left\{\frac{\beta}{1-\beta} \ln (A)+\ln \left(1-\beta+\beta \eta^{*}\right)-\frac{\beta}{1-\beta} \ln \frac{A \eta^{*}}{1-\beta+\beta \eta^{*}}\right\} \\
= & \frac{1}{1-\beta}\left\{\ln \left(1-\beta+\beta \eta^{*}\right)-\frac{\beta}{1-\beta} \ln \frac{\eta^{*}}{1-\beta+\beta \eta^{*}}\right\} \\
= & \frac{1}{(1-\beta)^{2}} \ln \frac{1-\beta+\beta \eta^{*}}{\left(\eta^{*}\right)^{\beta}} \\
> & 0 .
\end{aligned}
$$

Here, the last inequality follows from the fact that the function $f(\eta) \equiv \eta^{-\beta}(1-$ $\beta+\beta \eta)$ defined is monotonically decreasing for $\eta \in[0,1]$, and takes the minimum $f(1)=1$. Therefore, we have proved that all agents are better off in the equilibrium with complete markets than in the bubbly equilibrium. 


\section{References}

Abel, A. B., Mankiw, N. G., Summers, L. H., Zeckhauser, R. J., 1989. Assessing dynamic efficiency: Theory and evidence. The Review of Economic Studies 56 (1), 1-19.

Aoki, K., Nikolov, K., 2012. Bubbles, banks and financial stability. ECB Working paper 1495 .

Bewley, T., 1980. The optimum quantity of money. In J. H. Kareken and N.Wallace (eds.), Models of Monetary Economies.

Bewley, T., 1986. Stationary monetary equilibrium with a continuum of independently fluctuating consumers. Contributions to mathematical economics in honor of Gérard Debreu.

Constantinides, G., Duffie, D., 1996. Asset pricing with heterogeneous consumers. Journal of Political Economy 104 (2), 219-240.

Farhi, E., Tirole, J., 2012. Bubbly liquidity. The Review of Economic Studies $79(2), 678-706$.

Green, E., Zhou, R., 2005. Money as a mechansim in a Bewley economy. International Economic Review 46 (2), 351-371.

Grossman, G., Yanagawa, N., 1993. Asset bubbles and endogenous growth. Journal of Monetary Economics 31 (1), 3-19.

Hirano, T., Yanagawa, N., 2010. Asset bubbles, endogenous growth, and financial crisis. Working Paper, University of Tokyo.

Kitagawa, A., 1994. Risky storage and the value of money. Economics Letters $45,73-77$. 
Kitagawa, A., 2001. Money hoarding as a behaviour towards uninsured idiosyncratic risks. Japanese Economic Review 52 (1).

Krebs, T., 2003. Human capital risk and economic growth. The Quarterly Journal of Economics 118(2), 709-744.

Lucas, R. E., 1987. Models of business cycles. Oxford: Basil Blackwell.

Martin, A., Ventura, J., 2012. Economic growth with bubbles. American Economic Review 102(6), 3033-3058.

Meghir, C., Pistaferri, L., 2004. Income variance dynamics and heterogeneity. Econometrica 72 (1), 1-32.

Miao, J., Wang, P., 2014. Sectoral bubbles, misallocation and endogenous growth. Journal of Mathematical Economics (forthcoming).

Olivier, J., 2000. Growth-enhancing bubbles. International Economic Review $41(1), 133-152$.

Palacios-Huerta, I., 2003. An empirical analysis of the risk properties of human capital returns. American Economic Review, 948-964.

Saito, M., 1998. A simple model of incomplete insurance: The case of permanent shocks. Journal of Economic Dynamics and Control 22, 763-777.

Tirole, J., 1985. Asset bubbles and overlapping generations. Econometrica 53 (6), 1499-1528. 
Figure 1. Idiosyncratic production risk and bubble existence

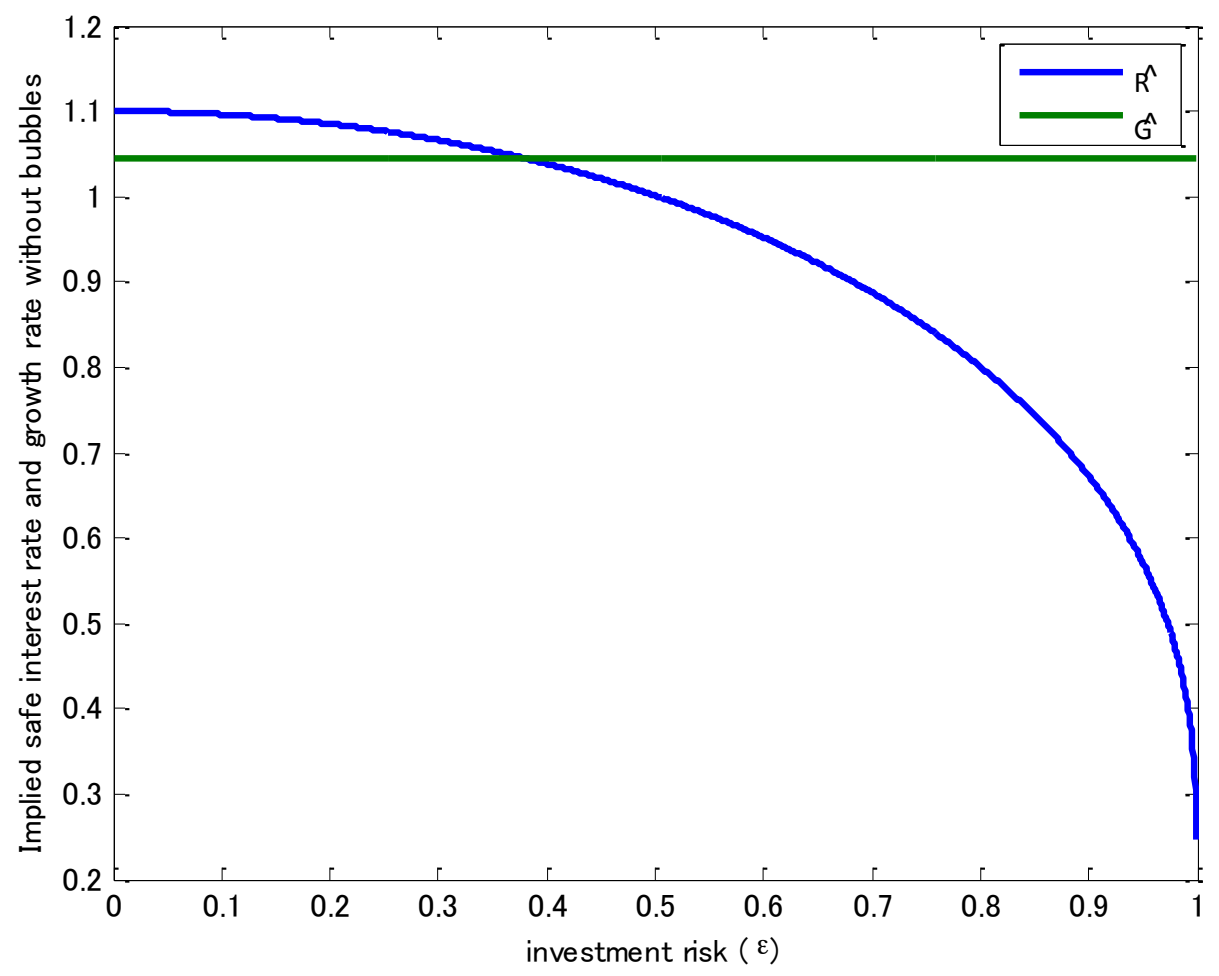


Figure 2: Idiosyncratic production risk and the share of the bubble asset in household portfolios

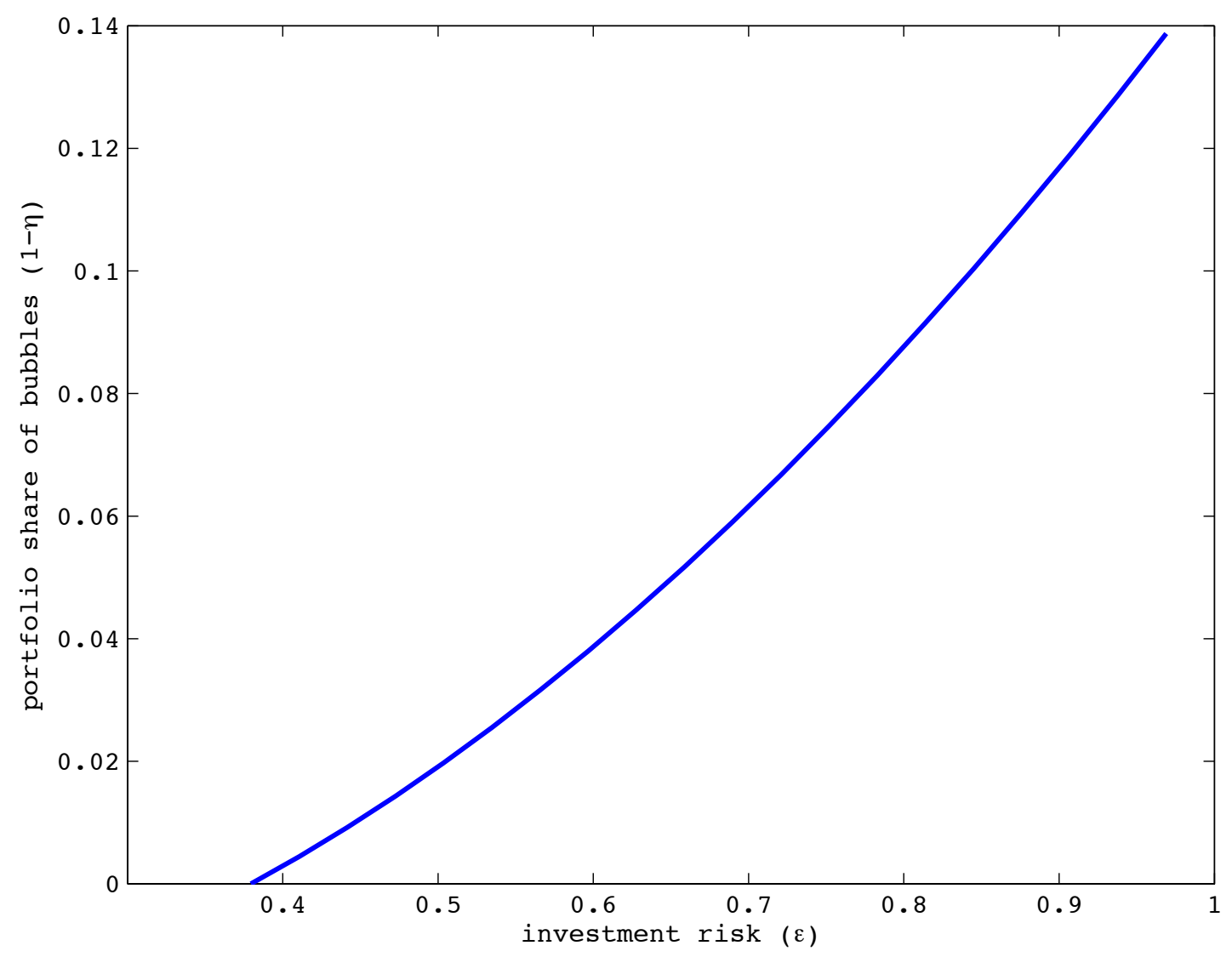


Figure 3: Idiosyncratic production risk and output growth with and without bubbles

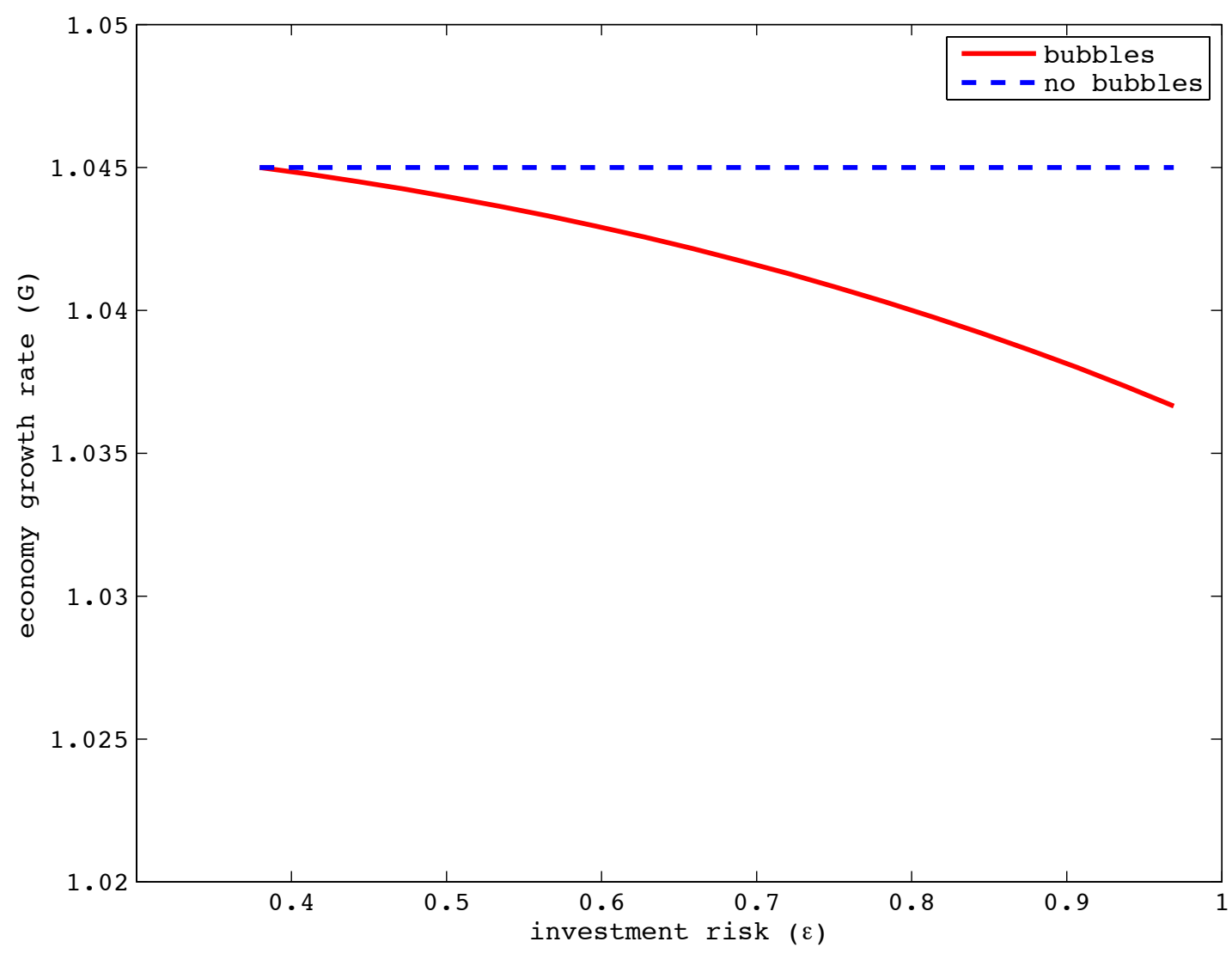


Figure 4: Idiosyncratic production risk and consumption growth volatility with and without bubbles

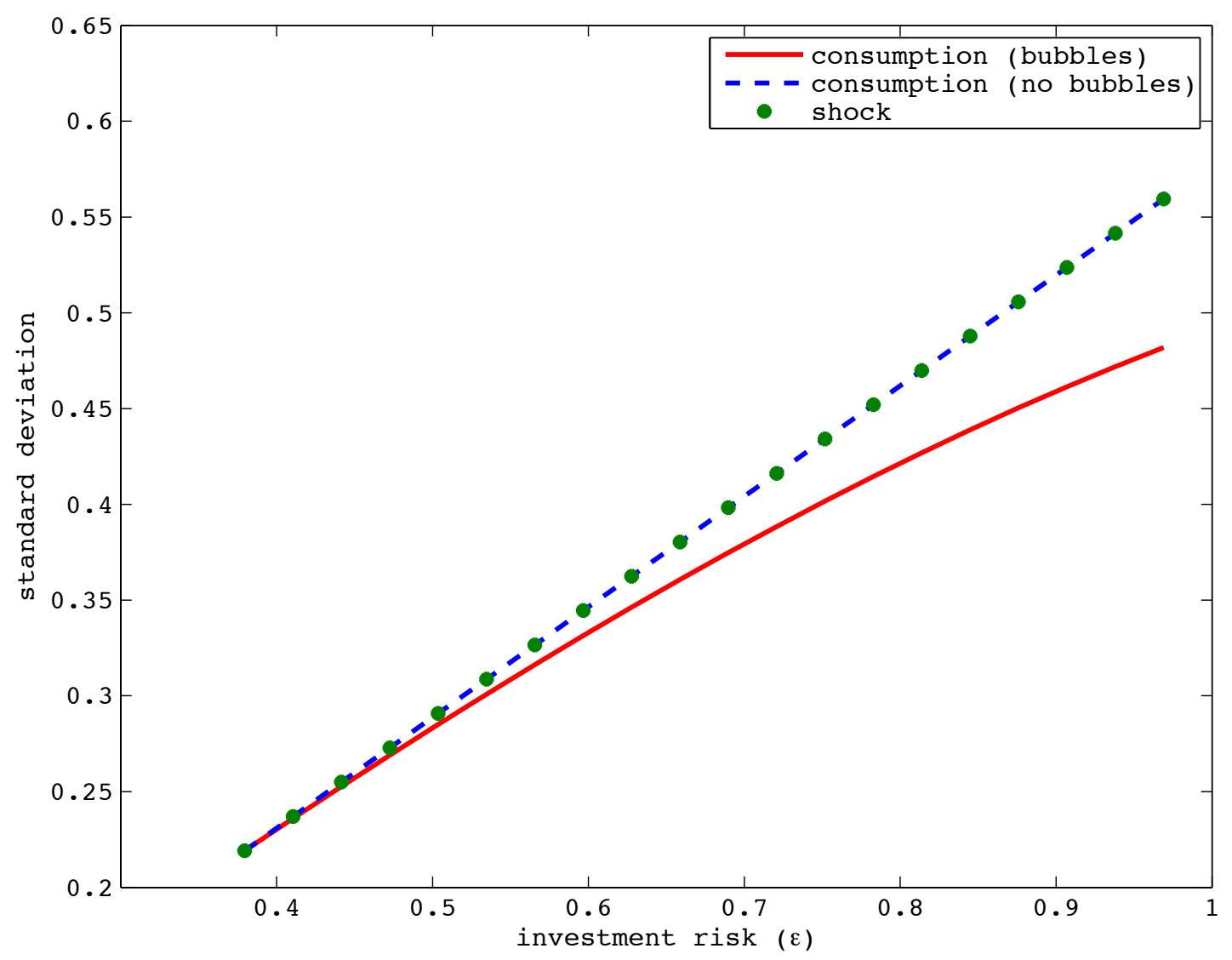

